\title{
FRANCISCANOS Y FRANCISCANISMO EN LA POLÍTICA Y EN LA CORTE DE LA CASTILLA TRASTÁMARA (1369-1475)
}

\begin{abstract}
SUMARIO
1. Los conflictos políticos internos.- 2. La intervención en la gestión política: a) La Corte y la Administración Central, b) La política exterior.- 3. Los confesores reales.- 4. Franciscanismo y política eclesiástica.- 5. El franciscanismo como devoción en la realeza Trastámara.- 6. Conclusión.- Prosopografía político-eclesiástica franciscana de Castilla (1366-1475).
\end{abstract}

Una línea de investigación de la historia bajomedieval castellana hasta la fecha inexplorada es aquélla que se refiere al estudio de la proyección política que alcanzaron algunas de las órdenes religiosas más significativas del momento, constituyendo, por tanto, tal cuestión un nuevo apartado dentro del estudio de la indudable significación política de la Iglesia en los tiempos medievales, tanto desde su perspectiva individual como institucional.

La elevada consideración que, en general, merecieron las órdenes mendicantes para la monarquía castellana, al igual que sucedió con otras monarquías occidentales, facilitó que algunas de estas órdenes, en particular Dominicos y Franciscanos y, para el caso específico castellano y ya de forma más tardía, Jerónimos, pusieran a un buen número de sus representantes en la escena política, desarrollando un protagonismo político, bien de forma directa o bien desde un segundo plano, cuyo análisis merece la pena emprender a fin de obtener una visión más completa de las realidades políticas de la época.

Sin pretender, ni mucho menos, agotar el tema, sino buscando, por el contrario, definir un esbozo inicial del mismo, recogiendo y analizando algunos pocos primeros materiales que puedan ser considerados como básicos en una primera aproximación, se abordarán algunas de las principales manifestaciones de aquéllas en las que se puso de relieve la proyección política del franciscanismo castellano durante el período de la monarquía Trastámara hasta alcanzar el comienzo del reinado de los Reyes Católicos que, también en este aspecto, representó una amplificación de tendencias anteriormente observadas. Así se considerará la actitud personal o institucional de los franciscanos en el desarrollo de los conflictos políticos de la época, su presencia en las actividades de gestión política del reino, su participación en las 
labores de servicio religioso para la realeza o para la Corte -siendo muchas veces esta forma de actuación básica en la posterior significación política alcanzada por algunos de los individuos dedicados a este tipo de actividades-, la proyección franciscana de la política eclesiástica de la realeza Trastámara, que afectará a cuestiones tan distintas como la incorporación franciscana al episcopado, el desarrollo de la reforma observante en el franciscanismo castellano o el impulso recibido por la actividad fundacional en este período; asimismo, habrá que prestar atención a la consideración del franciscanismo como una forma más de devoción de la realeza Trastámara, lo que, en algunos casos, facilitó esta proyección política que ahora nos interesa. Finalmente, como claro reflejo sistematizado de los resultados de este estudio, se incluirá una relación prosopográfica que, sin pretensiones totalizadoras, recogerá la trayectoria político-eclesiástica de los miembros de la Orden Franciscana aquí considerados, siendo el método prosopográfico un auxiliar fundamental en la investigación de este tipo de cuestiones.

\section{LOS CONFLICTOS POLÍTICOS INTERNOS}

En general, la participación de los franciscanos en la conflictiva vida política de la Castilla Trastámara fue bastante limitada, teniendo un carácter muy puntual que habitualmente se mantuvo en un muy segundo orden dentro del desarrollo seguido por los acontecimientos.

Sobre la vinculación de individuos o instituciones procedentes del franciscanismo al triunfo de la revolución Trastámara se puede ir bien poco más allá de la simple especulación. Sabemos que fueron muchos los conventos franciscanos, como de otras órdenes, que se vieron muy favorecidos por las donaciones y los privilegios otorgados por Enrique II ya desde fecha muy temprana, incluso desde 1366. Una buena parte de estos conventos se situaron, precisamente, en algunas de las zonas más afectadas por la guerra civil, lo que podría dar pie a la sospecha de que hubieran actuado como señalados colaboradores del pretendiente trastamarista; sin embargo, apenas se puede ir más allá de la sospecha. Lo cierto es que el favor regio se prolongó posteriormente a la propia guerra civil, convirtiéndose en un ejemplo a seguir por el conjunto de la nobleza.

No obstante, con carácter local, se ha llamado la atención sobre algún caso de monasterio franciscano en el que cabe apreciar una cierta significación política en los conflictos surgidos de la revolución Trastámara. Así, por ejemplo, el convento de San Francisco de Cuéllar, con estrechas relaciones con la hidalguía local y con algunos miembros destacados de la familia real '. Pero, a falta de datos más relevadores, habrá que concluir negando la realización de un papel significativo del franciscanismo en el desarrollo de la revolución Trastámara.

Ya durante los conflictos que enfrentaron a la monarquía de Juan II con buena parte de su nobleza, encabezada por los infantes de Aragón, se producirá la intervención ocasional en los acontecimientos de algún fraile franciscano, sin que tampoco, en ningún caso, se trate de actuaciones que alcancen un gran valor político. Así, por ejemplo, en 1427, Juan II encargará la mediación entre los nobles sublevados y don

1. José GARCIA ORO, Rrancisco do ANds en la Esparta Madioval, Santiago de Compostela, 1988, p. 324. 
Álvaro de Luna al franciscano fray Francisco de Soria, llegado a Castilla con motivo de actuar como embajador de Navarra ante el rey castellano y que alcanzará un rápido reconocimiento en los medios cortesanos castellanos, tal como lo demuestra la buena acogida que esta designación como mediador tuvo entre todas las partes implicadas en el conflicto ${ }^{2}$.

Unos años más tarde, en 1434, fue descubierto un complot por el que el conde de Luna, don Fadrique, había promovido ciertos tratos con diversos caballeros y personas de Sevilla a fin de conseguir esta ciudad para la facción de la nobleza opuesta a Juan II. Como consecuencia de ello, sería apresado el propio conde de Luna así como uno de sus más estrechos colaboradores en la preparación de esta empresa, un fraile franciscano, de origen portugués, cuyo nombre no se revela en las crónicas que dan noticia de estos hechos ${ }^{3}$.

En el transcurso de este mismo reinado tuvo lugar el brote herético conocido como los herejes de Durango. Sin embargo, no cabe advertir en el mismo consecuencias políticas de ninguna índole, hallándose su origen en la iniciativa predicadora del franciscano fray Alfonso de Mella ${ }^{4}$.

El reinado de Juan II cuenta entre los acontecimientos políticos que cierran su conflictiva trayectoria el ajusticiamiento de don Álvaro de Luna en Valladolid, en 1453. En dicho acontecimiento tuvo un cierto protagonismo un destacado fraile franciscano, al que habrá que aludir en repetidas ocasiones, fray Alonso de Espina. Éste fue designado por el mismo Consejo Real para que, haciéndose el encontradizo con don Álvaro, ya preso, le hiciera conocer el destino que se había decidido para él. Así, pues, si fray Alonso de Espina actuó como confesor de don Álvaro en sus últimos momentos, esta misión no fue, en primera instancia, al menos, religiosa, sino esencialmente política, al igual que otras realizadas por este religioso a lo largo de su vida .

Sería precisamente este mismo religioso franciscano quien protagonizaría unos años más tarde, en 1462, junto con otro franciscano, fray Fernando de la Plaza, una actuación que evidenciaba el reavivamiento del conflicto converso, al denunciar las supuestas prácticas judaizantes de algunos cristianos conversos que seguían realizando la circuncisión en sus hijos, lo que finalmente no se pudo demostrar, lo que dio pie a la intervención ante el mismo Enrique IV de un grupo de jerónimos, encabezados por su Prior General, fray Alonso de Oropesa, que predicarían contra estas acusaciones, sin que los franciscanos citados supieran estar a la altura de las circunstancias, a pesar del gran renombre de fray Alonso de Espina como predicador, estimándose, por ello, la falsedad de las acusaciones ${ }^{6}$.

2. Ángel URIBE, Primer ensayo de reforma franciscana en Espatia. Congregación de Santa Maria la Real de Tordesillas, «Archivo Ibero-Americanow, XIV (1985), p. 248.

3. Cónica del Halconero de Don Juan II de Castilla, edic. de Juan de Mata Carriazo, Madrid, 1943, cap. CLVIII, p. 149 y cap. CLX, p. 151-152.

4. Entre los trabajos más recientes sobre esta cuestión, en el que se reúne toda la bibliografía anterior al mismo: José GOÑI GAZTAMBIDE, Los herejes do Durango. Nuevas aportaciones (1442), «Hispania Sacra", XXXVIII (1975), 225-238. 430.

'. Cónica de Don Álvaro de Luna, edic. de Juan de Mata Carriazo, Madrid, 1943, cap. CXXVIII, p. 429.

6. Diego ENRJQuez del CASTILlO, Cónica del Rey Don Enrique el Cuarto, BAE, LXX, Madrid, 1953, cap. LIII, p. 130. 
Cuando se produzca la guerra civil que tiene lugar en Castilla a partir de 1465, como consecuencia del destronamiento en efigie de Enrique IV por una facción de la nobleza, tendrá lugar una profunda división en el seno de la Iglesia castellana, división que queda evidenciada por la diversidad de posturas que se observa entre el episcopado, que quedará escindido en tres partes, casi idénticas por el número, de miembros que las integraron: los favorables a Enrique IV, los favorables al príncipe don Alfonso y los neutrales. En aquel momento, sólo había un franciscano como obispo de una sede castellana, éste era fray Alonso de Palenzuela, que ocupaba la mitra de Ciudad Rodrigo. Éste se integrará en el grupo de los que se mantendrán neutrales, no variando su posición, por contra de otros prelados, en todo el desarrollo del conflicto ?.

Ya fallecido Enrique IV, en el transcurso del enfrentamiento que protagonizará el arzobispo de Toledo frente a sus antiguos aliados, los Reyes Católicos, se producirá de nuevo una actuación mediadora por parte de algunos religiosos franciscanos entre las dos partes en conflicto. Así, conociendo la devoción de la reina Isabel por los frailes menores, don Alfonso Carrillo y el Marqués de Villena, deseando una reconciliación con ella que se planteaba muy difícil, buscarán la mediación de algunos de estos religiosos para que ablandasen lo que parecía plantearse como una posición inflexible, consiguiéndose el objetivo perseguido ${ }^{8}$.

Por último, conviene señalar el destacado papel jugado por algún convento franciscano en los conflictos políticos locales que con cierta frecuencia se produjeron en algunas ciudades castellanas. Este será el caso de San Francisco de Jerez, que desarrollaría un considerable protagonismo en la conflictiva vida política jerezana de todo el conjunto del siglo XV. En unas ocasiones actuarían algunos de los frailes de este monasterio como representantes ante el concejo de los intereses del monarca. En otros casos, se comprometerían en los propios conflictos de la ciudad, al tomar un partido determinado ante la frecuente formación de bandos en su seno u, otras veces, finalmente, influirían en la evolución de los hechos con su consejo, como consecuencia del gran reconocimiento popular con el que contaban, por lo que su opinión fue, en momentos particularmente graves, tenida en cuenta para resolver pendencias tocantes a la vida política de la ciudad".

\section{LA INTERVENCIÓN EN LA GESTIÓN POLÍTICA}

La presencia de los franciscanos en las actividades referentes a la gestión o administración política del reino, al igual que sucede con los eclesiásticos en general, se produce, sobre todo, en dos ámbitos: por un lado, por su actuación en algunas de las principales instituciones de la administración central y de la Corte y, por otro lado, por sus intervenciones por encargo regio en misiones diplomáticas relacionadas con la política exterior castellana, particularmente intensa durante todo el conjunto

\footnotetext{
7 Diego de VAlerA, Memorial de diversas hazantas, BAE, LXX, Madrid, 1953, cap. XXXI, p. 35.

8 Fernando del PUlgar, Crónica de los Señones Reyes Católicos Don Fernando y Doña Isabel de Castilla y Aragón, BAE, LXX, Madrid, 1953, cap. LX, p. 313.

- Hipólito SANCHO, San Francisco el Real de Jerez de la Frontera en el siglo XV, "Archivo Ibero-Americano», V (1945), pp. 379-388.
} 
de la época Trastámara y en donde los franciscanos desempeñarán un notable papel como negociadores al servicio de la monarquía castellana.

\section{a) La Corte y la Administración Central}

La presencia de franciscanos en la Corte y en Administración Central realizando actividades de significación política se produce, sobre todo, bajo la condición de consejeros reales, sin que, en la mayoría de los casos, se pueda determinar si tal apelativo responde a personas que han sido llamadas a la Corte eventualmente por el monarca para expresar su opinión sobre un asunto específico o si se trata de miembros de lo que conocemos institucionalmente como el Consejo Real, a partir de su plena configuración por Juan I, o si son, finalmente, miembros del círculo de cortesanos que acompaña habitualmente al rey durante largos períodos de tiempo, teniendo, así la oportunidad de influir en las principales decisiones políticas de éste.

Uno de los consejeros franciscanos que probablemente a lo largo de su vida se halló en las tres situaciones a las que se acaba de aludir y de forma, además, más continuada, durante cuatro reinados - los de Enrique II, Juan I, Enrique III y Juan II- y de manera extraordinariamente activa fue, sobre todo, fray Fernando de Illescas, tratándose de una de las figuras más sobresalientes del franciscanismo castellano, en su dimensión política, de todo el conjunto de la Baja Edad Media castellana, pudiéndose ver en él un digno precursor de la figura de un Cisne$\operatorname{ros}{ }^{10}$.

Sobre su actividad en tiempos de Enrique II se poseen pocos datos; sin embargo, ya debía poseer un cierto relieve político su persona a la muerte de este monarca si se tiene en cuenta que el papa aviñonés Clemente VII, conociendo la gran influencia que poseía este eclesiástico en la Corte castellana, lo nombrará, el 3 de agosto de 1382, Capellán Pontificio ". Será precisamente durante el reinado de Juan I cuando la figura de fray Fernando de Illescas alcance un mayor relieve político. A ello no debió de ser del todo ajeno la vinculación del franciscano al círculo de eclesiásticos encabezado por el arzobispo toledano don Pedro Tenorio. En el entorno de esta figura aparecerán en el transcurso del reinado de Juan I toda una serie de eclesiásticos que durante éste y los reinados más inmediatos ocuparán posiciones de notable relevancia política. Así, éste será el caso, además del ya mencionado fray Fernando de Illescas, de otros como, por ejemplo, don Álvaro de Isorna, obispo de Cuenca, don Juan Serrano, prior de Guadalupe y, más tarde, obispo de Sigüenza, don Pedro Fernández de Frías, obispo de Osma, don Gutierre Gómez de Toledo, obispo de Oviedo, o don Diego de Anaya y Maldonado, obispo de Tuy, primero y, luego, de Salamanca ${ }^{12}$. Por otra parte, es indudable que la condición de confesor real que

10 Atanasio LÓPEZ, Fray Fernando de Illescas, confesor de los Reyes de Castilla Juan I y Enrique III, "Archivo Ibero-Americanow, XXX (1928), 241.

11 lbid., p. 244.

12 Luis SUÁREZ FERNÁNDEZ, Nobleza y Monarquia. Puntos de vista sobre la bistoria política de Castilla en el siglo XV, Valladolid, 1972, 2a edic., p. 35. 
ostentó fray Fernando de Illescas no debió de ser extraña a su propia promoción política. Sin embargo, a pesar de las repetidas alusiones a fray Fernando como consejero regio, sus actuaciones políticas, por lo general, se produjeron más en el marco de la política internacional castellana, como avezado negociador al servicio de los intereses de los monarcas castellanos, que como alguien particularmente embebido en las intrigas cortesanas tan propias de la época. Esto, junto a su condición ya citada, de confesor real, hará que hayamos de retomar su figura más adelante.

Durante el reinado de Juan II, entrará en escena en los medios cortesanos un fraile franciscano que tendrá un cierto protagonismo político a fines de la década de los años veinte del siglo XV, así como en la década siguiente. Éste es fray Francisco de Soria, quien habría llegado a Castilla en misión diplomática siendo confesor real de Juan I de Navarra. Según algunos cronistas franciscanos, sería consultado por el rey Juan II de Castilla para diversos asuntos políticos particularmente complejos ${ }^{13}$. Ya se aludió antes a su mediación, por encargo real, entre los Grandes castellanos y don Álvaro de Luna en 1427, lo que fue bien aceptado por todos por ser considerado este fraile como «santo e bueno». En los primeros meses de 1429 era enviado por el mismo monarca como su representante ante el rey de Navarra, para que evitase su entrada en Castilla junto con el rey de Aragón, siendo una de sus últimas actuaciones su actividad como inquisidor regio en el caso de los herejes de Durango ${ }^{14}$. A todo ello, habría que añadir su colaboración en la política reformadora impulsada por la realeza en favor de la observancia franciscana, pero ello será objeto de atención más adelante ${ }^{15}$.

Un consejero de excepción al servicio de Juan II habría sido -si es que realmente llegó a serlo- San Pedro Regalado. Su actuación como tal debió de ser, en cualquier caso, muy ocasional, produciéndose, seguramente, mientras estuvo como vicario en el eremitorio del Abrojo, a poca distancia de Valladolid, donde se encontró frecuentemente reunida la Corte en los últimos años del reinado de este monarca, considerando algunos autores como particularmente intensa su influencia sobre el monarca en los momentos inmediatos a la caída de Don Álvaro de Luna ${ }^{16}$.

Ya con Enrique IV tuvo la condición de consejero real fray Alonso de Palenzuela, desarrollando una rápida carrera política y, paralelamente, eclesiástica, que le llevó a ocupar las mitras de Ciudad Rodrigo (1460-1469) y de Oviedo (1469-1470). También en este caso, al igual que sucedió con fray Fernando de Illescas, sus misiones políticas se realizan sobre todo por vía de actividad diplomática. Pero los paralelismos con la trayectoria vital de fray Fernando de Illescas no se quedan sólo en eso. También fue fray Alfonso de Palenzuela, como aquél, confesor real, siendo a partir de ese momento cuando se producirá su despegue como personaje de relieve político, entre cuyas empresas se contará su colaboración con el legado pontificio

13 Fidel LEJARZA y Ángel URIBE, Introducción a los origenes de la Observancia en España en los siglos XIV y $X V$, « Archivo Ibero-Americanow, XVII (1957), pp. 497-499.

14 Ángel URIBE, Art. cit., pp. 248-249.

19 Pedro CARRILlO De HUETE, Refundición de la Crónica del Halconero, edic. de Juan de Mata Carriazo, Madrid, 1943, cap. XXXII, pp. 66-67 y Crónica del Halconero, cap. VIII, p. 28. Aquí ya es citado como franciscano observante.

16 Fidel LejARZA y Ángel URIBE, Introducción, pp. 496- 498. 
Antonio de Veneris en la guerra civil entre Enrique IV y los partidarios del príncipe don Alfonso ${ }^{17}$.

Una responsabilidad política que de hecho se traducía en lo que se podría considerar como la actividad propia de un consejero real, yendo incluso, a veces, más lejos de lo que esto suponía, es la del testamentario real, es decir, el encargado de vigilar el estricto cumplimiento de todas y cada una de las últimas voluntades del monarca fallecido, lo que implicaba a veces una inmersión de lleno en los asuntos más sustanciales de la política del momento. Tal responsabilidad recayó en alguna ocasión sobre representantes de los franciscanos. Este fue el caso por ejemplo, de dos de los testamentarios nombrados por Enrique III en 1407: fray Juan Enríquez, ministro de la orden franciscana, y el ya mencionado fray Fernando de Illescas, por entonces confesor del rey, compartiendo esta condición con el condestable Ruy López Dávalos y el obispo de Cartagena, don Pablo de Santa María, por entonces canciller mayor del príncipe don Juan ${ }^{18}$. Fray fernando de Illescas volvería a recibir este mismo encargo en el testamento de doña Catalina de Lancaster, en $1418^{19}$.

\section{b) La politica exterior}

La intensa política exterior desarrollada por la monarquía Trastámara supuso la presencia asidua en actividades de representación ante Cortes extranjeras, en nombre de la realeza castellana, de un nutrido número de eclesiásticos. Una parte significativa de éstos pertenecieron precisamente a la Orden de San Francisco.

Por lo que se refiere a las relaciones entre Castilla y Aragón, en 1414, fray Alfonso de Argüello, por entonces obispo de León, fue enviado a la Corte aragonesa para estar presente en representación de los castellanos en la coronación de don Fernando de Antequera, de quien había sido un estrecho colaborador, lo que le llevaría a ocupar poco después la mitra arzobispal de Zaragoza, siendo asesinado como titular de la misma ${ }^{20}$. También representaría don Afonso de Argüello al rey de Castilla, junto con otros eclesiásticos, en 1415 , con motivo de la boda celebrada en Aragón entre el príncipe don Alfonso, hijo del rey aragonés, y la infanta María de Castilla ${ }^{21}$.

En las relaciones con el ámbito inglés tuvo, a fines del siglo XIV, un especial protagonismo fray Fernando de Illescas, en especial, cuando tenía lugar la invasión del Duque de Lancaster ${ }^{22}$. Un continuador de esta actividad diplomática con Inglaterra por parte franciscanista será, ya con Enrique IV, fray Alonso de Palenzue-

17 Diego EnRíQUeZ Del CaSTILlo, Crónica, cap. XXVI, p. 114. Memorias de Enrique IV de Castilla, edic. de la Real Academia de la Historia, Madrid, 1835-1913, II, doc. CXLIV, pp. 541-545 (Westminster, 6-VII1467).

18 Pero LóPeZ DE AYAla, Crónica de Enrique III de Castilla, BAE, LXVIII, Madrid, 1953, cap. XVI, p. 263. BIBLIOTECA NACIONAL, Ms. 6.932, fol. 352.

19 Manuel de CASTRO, El Real Monasterio de Santa Clara de Palencia y los Enríquez, Almirantes de Castilla, Palencia, 1982, p. 62.

20 Crónica de Juan II de Castilla, BAE., LXVIII, año VIII, cap. II, p. 358.

21 lbid., año IX, cap. III, p. 362.

22 Pero LÓPEZ DE AYAlA, Cónica de Juan I de Castilla, BAE, LXVIII, cap. I, p. 118 y cap. III, p. 123. 
la, que se encargará de establecer, en 1467, en nombre del rey castellano, una alianza entre Castilla y Eduardo IV de Inglaterra en $1467^{24}$, teniendo ya por entonces una importante experiencia adquirida en actividades diplomáticas, como consecuencia de sus actividades de representación ante la Santa Sede en años anteriores ${ }^{24}$.

En las relaciones con Francia, las únicas actividades diplomáticas documentadas, por parte de franciscanos castellanos, se refieren de nuevo a Fray Fernando de Illescas, en 1396, ocurriendo otro tanto para las relaciones con Navarra, acudiendo fray Fernando a Estella en 1383 para entrevistarse con el rey navarro, quien le enviaría algunos regalos dos años más tarde. En 1389 también efectuaría actividades diplomáticas ante la Corte portuguesa a fin de asegurar la paz entre Castilla y Portu$\mathrm{gal}^{25}$.

Las relaciones de Castilla con el Papado estuvieron durante mucho tiempo centradas casi exclusivamente en la solución al problema planteado por el Cisma. Ello tuvo especial importancia, desde el punto de vista de la preparación en materia de relaciones internacionales de un buen número de eclesiásticos sobre los que recayó de forma más habitual la ejecución de estas actividades de representación ante la Corte Pontificia. Algunos de estos clérigos pertenecerían a la Orden Franciscana.

Entre las primeras misiones enviadas por Castilla con motivo del Cisma estaría la realizada entre 1380 y 1381 por fray Fernando de Illescas, enviado a la Corte aviñonesa, en compañía de Ruy Bernárdez y Alvaro Meléndez, a fin de recabar toda la información posible sobre el Cisma, por lo que luego se trasladaría, continuando con esta misión, a Roma y Nápoles, presentando un informe favorable a Clemente VII y contrario a Urbano VI, aceptando ser nombrado por aquél visitador de las clarisas de Tordesillas, lo que pone de manifiesto claramente la aceptación de su legitimidad, influyendo sobre Juan I para inclinarse por el partido clementino, lo que se confirmaría en la asamblea de Salamanca de $1381^{26}$. En 1397 era enviado a Aviñón fray Alonso de Argüello, junto con el doctor Alfonso Rodríguez, en calidad de embajadores del rey de Castilla, siguiéndoles dos años más tarde fray Fernando de Illescas, como miembro de una nutrida embajada enviada para entrevistarse con el Rey de Romanos y otros príncipes a fin de dar una solución rápida al Cisma. Fray Alfonso de Argüello reaparece otra vez en 1401 en las actividades diplomáticas para ejecutar la decisión del rey castellano de aceptar la obediencia a Benedicto XIII. Cuatro años más tarde, el intento de Enrique III de imponer la "vía compromissi» como solución final al Cisma dará origen a nuevas embajadas, entre cuyos miembros franciscanos encontramos, en 1405, a fray Alfonso de Alcocer ${ }^{27}$ y, en 1406, a fray

23 Memorias de Enrique IV de Castilla, II, doc. CXLIV, pp. 541-545.

24 Véanse: «Archivo Ibero-Americanow, III (1943), pp. 117 y $561-562$ y Luis SUÁREZ FERNÁNDEZ, Política internacional de Isabel la Católica. Estudios y Documentos, I (1468-1481), Valladolid, 1965, pp. 288289.

25 Véanse: José GOÑı GAZTAMBIDE, Los españoles en el concilio de Constanza. Notas biográficas, Madrid, 1966, p. 182; Atanasio LÓPEZ, Fray Fermando de Illescas, p. 245, y Pero LÓPEZ DE AYALA. Crónica de Juan II, año XI, cap. VI, pp. 124-125.

26. Atanasio LÓPEZ, Fray Fernando de Illescas, p. 243.

27 Sobre estas embajadas, véanse: Atanasio LÓPEZ, Fray Fernando de Illescas, pp. 248; Luciano SERRANO, Los conversos don Pablo de Santa Maria y don Alfonso de Cartagena, Madrid, 1942, p. 35; Toribio MINGUELLA ARNEDO, Historia de la diócesis de Sigüenza y de sus obispous, Madrid, 1911, II, pp. 118-120; Luis SUÁREZ FERNÁNDEZ, Castilla, el Cisma y la crisis conciliar, Madrid, 1960, pp. 46, 56-58 y apénd. doc., docs. 69 y 71. 
Rodrigo Martínez de Lara ${ }^{28}$. Ya en los momentos inmediatos a la reunión conciliar de Constanza, destacará en la Corte castellana fray Juan Enríquez como ardiente defensor de la sustracción a la obediencia de Benedicto XIII y por la imposición de una solución conciliar, línea de pensamiento opuesta a la de Catalina de Lancaster y a la de algunos destacados e influyentes eclesiásticos, como los arzobispos de Toledo y Sevilla ${ }^{20}$. Cuando, en 1416, se envíe la embajada castellana ante el Concilio de Constanza, el único miembro franciscano de la misma será, una vez más, fray Fernando de Illescas "'.

Finalizado el conflicto del Cisma, no se volverán a producir nuevas embajadas castellanas ante el pontificado por parte de miembros de la Orden Franciscana hasta tiempos de Enrique IV. En 1457, fray Alonso de Palenzuela actuará como mediador entre el rey castellano y el papa Calixto III para ver la viabilidad de imponer un subsidio extraordinario sobre el clero castellano ". Precisamente, será este mismo fraile el que asista, en representación del rey de Castilla, a las exequias de Calixto III, al año siguiente, y para prestar la debida obediencia al nuevo papa elegido, Pío II "2, ante quien comparecerá, ya en 1463, otro embajador castellano de procedencia franciscana, fray Alfonso de Villarreal, por entonces lector en Teología ".

Junto a todas estas misiones diplomáticas, hay que recordar también cómo, de forma ocasional, entre 1444 y 1445, Eugenio IV utilizó un buen número de franciscanos castellanos a fin de influir en el ánimo del rey castellano para conseguir del reino de Castilla su apoyo para llevar a cabo la lucha contra los turcos, dirigida, sobre todo, a la protección de la isla de Rodas ${ }^{34}$. Entre estos franciscanos castellanos que acudirán ante Juan II con esta pretensión se encontrarán, por ejemplo, fray Alfonso de Borox, fray Fernando de Salamanca, fray Fernando de San Isidoro, fray Pedro de la Peña y fray Francisco de Orgaz ". Todos ellos nombrados luego colectores pontificios para la recaudación del correspondiente subsidio ${ }^{36}$, junto con los también franciscanos fray Luis de Saja ${ }^{37}$, que desarrollará luego una importante actividad reformadora en Castilla, y fray Pedro de Córdoba ${ }^{38}$.

\section{LOS CONFESORES REALES}

Los confesores reales constituyen la base fundamental de los religiosos francisca-

28 Manuel de CASTRO, Crónica de la provincia franciscana de Santiago, 1214-1614, Madrid, 1971, p. 56.

29) Luis SUÁREZ, Castilla, el Cisma y la crisis conciliar, p. 83.

30 José GoÑı GAZTAMBIDE, Los españoles en el Concilio de Constanza, p. 147.

3 Lucca WADDINGO, Annales Minorum, Lyon, 1642, VI, anno 1457, núm. XLII-XLIII, p. 183-184.

32 Diego de VAlerA, ob. cit., cap. XV, p. 18.

33 Atanasio LÓPEZ, El franciscanismo en España durante los pontificados de Eugenio IV y Nicolás IV a la luz de los documentos vaticanos, "Archivo Ibero-Americano», XXXV (1932), p. 546.

i1 La importante participación franciscana en esta embajada pontificia debió de ser acorde con la notable presencia de esta Orden en la Isla de Rodas, cuya defensa ante el turco se pretendía garantizar.

is Lucca WAdDingo, Ob. cit., p. 456. BibljoteCA NACIONAL, Ms. 3.840, fol. 65.

36. Bullarium Franciscanum continens Constitutiones, Epistolas, Diplomata Romanorum Pontificum Eugenii IV et Nicolai $V$ ad tres Ordines S.P.N. Francisci spectantia, Nova Series, vol. I (1431-1455), edic. de Ulrico Hüntemann, Florencia, 1929, n. 854. Atanasio LÓPEZ, El franciscanismo en España, p. 209.

37 Bullarium, I, n. 886. Atanasio LÓPEZ, El franciscanismo en España, p. 106.

38 Bullarium, I, p. 859 y Atanasio LÓPEZ, El franciscanismo en España, p. 208. 
nos dedicados de algún modo a la colaboración en el desarrollo de los objetivos políticos de los reyes castellanos. La presencia de muchos franciscanos como representantes diplomáticos del rey de Castilla, como mediadores en algunos conflictos políticos internos, como destacados partícipes en la política eclesiástica de reforma impulsada por los monarcas Trastámara, casi siempre pasa por un período de previo, generalmente, salvo excepciones, no muy extenso en el tiempo, de dedicación a las actividades propias de confesor real, sin que parezca que éstas se redujeran simplemente al auxilio espiritual del monarca y de su familia más próxima, sino que, por lo general, se compatibilizaban con la realización de diversas misiones por encargo del monarca y con el ejercicio de una notable influencia en algunas decisiones políticas regias. Es por ello que, para estos frailes franciscanos, el acceder al cargo de confesor real supuso, sin excepción, incorporarse a los vaivenes de la agitada vida política de la época.

No hubo monarca Trastámara que, en uno u otro momento de su vida, no contara con los servicios de algún confesor franciscano. No serían incluso raros los casos de algunos de estos confesores que prestasen sus servicios como tales a más de un monarca o que, a raíz de su actividad como confesor real, continuase su relación con la Corte mediante el ejercicio de funciones diversas.

La tradición seguida por los reyes de Castilla en materia de confesores reales daba preferencia a los de procedencia dominica y franciscana. Fiel a esta tradición, Enrique II, tras haber tenido por confesor durante su época de conde al franciscano fray Diego López de Ribadeneyra, maestro en Teología ${ }^{39}$, tendría durante el resto de su vida confesores de procedencia dominica ${ }^{40}$.

Juan I mostraría su preferencia por los confesores franciscanos, recayendo su elección sobre fray Fernando de Illescas. Cuando accedió a este puesto, fray Fernando había realizado estudios en el Colegio de Santiago de París, entrando en contacto con la Corte castellana cuando enseñaba en la Universidad de Valladolid. Debió de ser su fama como predicador lo que le abrió las puertas de la Corte, granjeándole el aprecio del propio monarca, siendo ésta una circunstancia bastante frecuente en los confesores reales de la época Trastámara ${ }^{41}$. Será a partir de convertirse en confesor real cuando progresará rápidamente en la escena política, asumiendo importantes responsabilidades que le llevarían a convertirse en uno de los personajes políticos más importantes de la Corte castellana, sobre todo durante las minorías de edad de Enrique III, del que sería ayo y sobre el que ejercería siempre una gran influencia, y de Juan II. Su preeminente posición también redundaría en favor de la elevación en sus respectivas carreras eclesiásticas de sus hermanos, Juan de Illescas, obispo de Sigüenza, y Alfonso de Illescas, obispo de Burgos.

Durante el reinado de Enrique III se observa un notable predominio de los franciscanos en el ejercicio del puesto de confesor real; tan sólo un dominico -fray Alonso Pérez de Cusanza- ocupará este puesto frente a dos franciscanos: fray Juan

39 Jose SÁNCHEZ HERRERO, Los obispos castellanos y su participación en el gobierno de Castilla, 1350-1406, en «Realidad e imágenes del poder en España a fines de la Edad Media. El siglo XV n, coord. A. Rucquoi, Valladolid, 1989. pp. 96.

40 Pero LÓPEZ AYALA, Crónica de Enrique Il, año XIV, cap. III, p. 37-38.

41 Atanasio LÓPEZ, Fray Fernando de Illescas, p. 242. 
Enríquez ${ }^{42}$ y fray Alfonso de Alcocer ${ }^{43}$, si bien el cronista Waddingo añadirá un tercer confesor franciscano, fray Alfonso de Aguilar, del que, en cambio, no consta otra noticia, pudiéndose tratar de una confusión con el ya citado fray Alfonso de Alcocer ${ }^{4}$. Fray Juan Enríquez abandonaría su cargo de confesor real como consecuencia de su nombramiento como Ministro Provincial de los Frailes Menores de la Provincia de Castilla, pudiendo ser él mismo quien recomendase a Enrique III su sustitución por fray Alfonso de Alcocer, quien, al igual que sucediera con fray Fernando de Illescas, realizaría importantes actividades diplomáticas al servicio de la realeza relacionadas con el problema del Cisma. El monarca debió de quedar plenamente satisfecho con sus servicios, și tenemos en cuenta que en su testamento se le citará para designarlo como confesor del futuro Juan II, con quien, efectivamente, ejercería tal responsabilidad mientras duró su minoría de edad hasta 1410, momento en que, al igual que antes sucediera con fray Juan Enríquez, fue nombrado Ministro Provincial de los Frailes Menores de Castilla, por lo que Catalina de Lancaster debió pedir a Benedicto XIII la correspondiente dispensa para que fray Alfonso de Alcocer pudiera abandonar sus actividades como confesor real, incumpliendo así las cláusulas testamentarias ". Precisamente, en el testamento de Enrique III, además de citarse a fray Alfonso de Alcocer como director espiritual del príncipe don Juan ${ }^{46}$, también será citado fray Juan Enríquez, además de como testamentario regio, junto con fray Fernando de Illescas y otros ya citados, como persona por la que el rey suplicaba al papa para que se le proveyera de una mitra episcopal, junto con el también confesor real de la Orden de los Predicadores fray Alonso Pérez de Cusanza ${ }^{47}$. Estas promociones episcopales de confesores reales por suplicación regia no serán nada raras en la época. Un buen ejemplo se puede encontrar, por estas mismas fechas, en fray Alfonso de Arguello, confesor del infante don Fernando de Antequera, mientras estuvo en Castilla, del que se convertiría en un estrechísimo colaborador, obteniendo por su mediación la mitra palentina ", de la que, por suplicación del ya Fernando I de Aragón, pasaría a ocupar el arzobispado de Zaragoza, a la vez que se convertía en Canciller de Aragón ${ }^{9}$.

Ya en tiempos de Juan II destacó como confesor real fray Alonso de Palenzuela, Provincial de los Observantes Franciscanos de la Provincia de Santiago, siendo uno de los primeros reformadores en favor de la observancia franciscana ${ }^{\text {so }}$. Su elección como confesor real de Juan II debió de ser, sobre todo, consecuencia de su prestigio como predicador y teólogo, siendo por ello nombrado también predicador real ".

42 José SÁNCHEZ HERRERO, art. antes cit., p. 97.

43 Atanasio LÓPEZ, Fray Alfonso de Alcocer, confesor de Enrique III do Castilla, «Archivo Ibero-Americanow, XXIX (1928), 369-374.

44 Lucca WADDINGO, ob. cit., V, anno 1407, p. 54.

45 Véase nota 43.

46 Biblioteca NACiONAL, Ms. 6.932, fol. 343.

47 lbid., fol. 350.

48 Lucca WADDINGO, ob. cit., V, anno 1418, p. 123.

49 A. Alvarez ReYero, Crónicas opiscopales palentimas, Palencia, 1898, p. 159.

so Manuel de CASTRO, Crónica de la provincia franciscana de Santiago, Pp. 38-39, 66, 117 y 961-362. Luis SUAREZ FERNANDEZ, Política internacional de Isabel la Catolica, I, pp. 288-289.

31 Espanta Sagrada, XXXIX, p. 70. 
Además de acceder a las mitras de Ciudad Rodrigo y de Oviedo, en donde destacaría como estricto cumplidor de las obligaciones episcopales, seguiría rindiendo servicios políticos en tiempos de Enrique IV ${ }^{\prime 2}$. De fray Alfonso de Palenzuela se conserva un homiliario, con un total de veintiséis homilías de san Juan Crisóstomo, con sus correspondientes comentarios y enseñanzas morales referidas al Evangelio de san Mateo ", resultando su consulta de sumo interés por ofrecer un extenso repertorio de los que serían algunos de los temas predilectos en las homilías de este famoso predicador de la Corte castellana, presentándonos una completa relación de lo que, en la época, serían las principales preocupaciones morales".

Dentro de la Corte castellana de Juan II se movería otro confesor real; éste lo era de la reina Doña María, fray Sancho de Canales, maestro en Teología ". Sería, precisamente, a partir de su relación con la reina como este confesor real desarrollaría, por encargo regio, una intensísima actividad reformadora en favor de la observancia franciscana, actuando, sobre todo en el transcurso de 1441, como reformador y visitador de numerosos conventos franciscanos, entre ellos los de Salamanca, Palencia, Soria y Molina ${ }^{\text {* }}$.

Comparativamente con los reinados anteriores, escasea la información sobre los confesores regios de tiempos de Enrique IV. Es posible que el propio fray Alfonso de Palenzuela actuase ocasionalmente como tal, sin embargo, es fray Alonso de Espina el que más habitualmente suele ser situado en este cargo. Así, Diego de Valera, refiriéndose a él, lo califica como bombre muy letrado y gran predicador, y añade que era oservante y Confesor del Rey ". De nuevo, parece que es la buena condición como predicador lo que resulta determinante para acceder al cargo de confesor real. Además de su mediación en favor de los observantes franciscanos, también nos es conocida su actuación como predicador de la cruzada en 1456, haciendo uso, en esta ocasión, de su confianza con el rey para recordarle lo reprobable de la utilización de los fondos de la cruzada para fines distintos de la guerra contra el infiel "s".

En suma, a partir de los datos recién expuestos, queda bien patente la continuidad de los franciscanos en labores de confesores reales con las que habitualmente irían asociadas unas ciertas actividades políticas que en una buena parte desconoce-

32 Diego de VAlerA, Memorial, cap. XV, p. 18.

" Biblioteca dil. Real. monasterio de SAN lorenzo de El. escorial, Ms. b.ll.18.

31 Las veintiséis cuestiones de orden moral que centran la temática de este homiliario de Fray Alonso de Palenzucla son las siguientes: Que la homilía se oiga sin sueño y con vigilia (I), lo mucho que aprovecha la meditación sobre las Sagradas Escrituras (II), sobre la humildad (III), de la conveniencia de la vida derecha y virtuosa (IV), contra la usura (V), sobre el juego) y el teatro (VI), sobre la administración de los sacramentos y la entrega de limosna (VII), de la vida de los monjes (VIII), sobre la avaricia y la codicia (IX), sobre la enmienda de los pecados y sobre la oración (X), sobre los falsos juramentos (XI), sobre la buena crianza (XII), sobre los consejos (XIII), sobre la memoria de los pecados y cómo se debe rogar por ellos (XV), de la vida virtuosa (XV), cómo lo difícil se hace fácil si se realiza por Dios (XVI), sobre los juramentos (XVII), de la humildad y sobre el saludo (XVIII), cómo no se debe maldecir a los enemigos y cómo se debe estar en el templo (XIX); el XX no contiene exhortación explícita; sobre la avaricia (XXI), cómo se debe saber elegir el bien pidiéndolo a Dios (XXII), cómo la nobleza da la vida virtuosa y no las riquezas ni el poderio (XXIV); el XXV no contiene exhortación moral expresa; de la vida virtuosa y de la malicia (XXVI).

35 Manuel de CASTRO, Crónica de la provincia franciscana de Santiago, p. 111.

36 Bullarinm, I, n. 524.

"Diego de Vallira, Memorial, p. 5.

sk lbid., p. 15. 
mos, siendo resultantes de su función de directores espirituales y de consejeros íntimos de los monarcas, no siendo ajeno a su función el consejo político.

\section{FRANCISCANISMO Y POLÍTICA ECLESIÁSTICA}

El conjunto de la historia castellana dominada por la presencia en el trono de la dinastía Trastámara, más aún si también tenemos en cuenta el reinado de los Reyes Católicos, se caracteriza por desarrollar una política eclesiástica una de cuyas principales componentes consistió en emprender una profunda reforma del clero castellano a fin de superar la decadencia en las costumbres del mismo que, tan frecuentemente, había sido denunciada ya desde comienzos del siglo XIV. Los monarcas de la dinastía Trastámara tomaron conciencia de que gobernar suponía también intervenir en orden al establecimiento de unos ideales de comportamiento religioso de los que el clero, en especial el clero regular, debía actuar como modelo a seguir. Ello no se hizo, desde luego, por consideraciones exclusivamente religiosas, sino que se creyó que el afianzamiento de unos comportamientos religiosos más modélicos, auspiciados desde la propia monarquía, podría contribuir a promover el fortalecimiento de la solidaridad política de los súbditos en torno a la propia realeza como expresión máxima de la comunidad política formada por el reino. Consecuencia de todo ello sería que, como resultado de la experiencia Trastámara, al término de la evolución medieval, las iniciativas de reforma eclesiástica quedaron reconocidas como una genuina competencia del poder regio. En esta política de reforma eclesiástica con intervención regia, las órdenes mendicantes y, entre ellas, la Orden Franciscana, tuvieron un protagonismo de primer orden.

La actuación regia en orden a provocar efectos de reforma eclesiástica se produjo, sobre todo, por dos vías: el establecimiento de un ideal episcopal, a partir del cual se irradiase una transformación en los comportamientos para todo el conjunto del clero, $y$, por otro lado, la incidencia sobre la vida monástica, a través de la expansión de la fórmula observante.

La imposición de un ideal episcopal responde a una etapa más tardía que la que aquí se considera, tratándose de una labor más propia de tiempos de los Reyes Católicos. Hasta entonces, lo que se va a producir será una intervención más sistemática e institucionalizada del poder regio en la provisión de las sedes episcopales. En este sentido, fueron varios los casos de provisiones por mediación regia que recayeron en favor de religiosos franciscanos en los que se buscaba una ejemplaridad en el ejercicio del oficio episcopal, tratándose de personas con reconocido prestigio como teólogos, predicadores y, a veces, como confesores por haberlo sido de la propia familia real o de miembros destacados de la Corte. Seguramente, el mejor ejemplo de todo ello esté representado por fray Alonso de Palenzuela, obispo de Ciudad Rodrigo, desde 1460, y de Oviedo, entre 1469 y 1470, siendo todo un modelo en el cumplimiento de sus obligaciones pastorales ${ }^{59}$.

39 "Y como quiera que muchos de los frailes de su Orden refutaban dél por haber tomado Obispado, él dio de sí tan buena quenta y vivio tan limpiamente, haciendo enteramente su oficio, confesando sus súbditos y predicándoles continuamente de tal manera que sirvió á Dios en recebir la dicha dinidad de Obispado, y desque ovo el Obispado de Oviedo, donde no menos sirvió á Dios que en el primerow. Diego de VALERA, ab. cit., cap. XV, p. 18. 
A pesar de la resistencia de los franciscanos observantes a aceptar la dignidad episcopal, para el período aquí considerado, hubo un total de veintidós prelados franciscanos, muchos de ellos provenientes de los medios observantes y, en su mayoría, promovidos a instancias regias. Fueron, sobre todo, las sedes episcopales con mayor significado misional -actividad en la que destacaban los franciscanos- las que recibieron un mayor número de prelados de esta procedencia. Así, por ejemplo, Málaga contaría con cuatro prelados franciscanos: fray Fernando Verguera (142023), fray Fernando de Algaria (1430-32), fray Martín de las Casas (1433-41) y fray Rodrigo de Soria (1458-86). Tres prelados franciscanos tendría la sede de Cádiz: fray Gonzalo González (1364-81), fray Rodrigo de Alcalá (1384-96) y fray Juan de Ezcaray (1395-1408); otros tres tendría la Sede canaria de Rubicón: fray Alonso de Sanlúcar (1404-1418), fray Mendo de Viedma (1418-31) y fray Francisco de Moya (1436-41); la sede de Guadix tendría dos: fray Fernando de Atienza y fray Pedro de Ocaña, y, finalmente, otras diez sedes contarían con un prelado de la Orden de los Menores: Astorga, Badajoz, Cartagena, Córdoba, Coria, León, Lugo, Oviedo, Plasencia y Sevilla.

Pero, tal como se avanzó, no fue la imposición de un modelo episcopal la forma más activa desarrollada por los monarcas para efectuar sus pretensiones de reforma eclesiástica, sino que éstas se canalizaron, sobre todo, por vía de incorporación de la observancia a la vida de conventos y monasterios, siendo el caso franciscano un buen exponente de este hecho.

Ya con anterioridad a la época Trastámara, se había establecido por los reyes castellanos un cierto compromiso de protección hacia los conventos franciscanos, tal como había establecido Sancho IV en 1285 , al recibir los conventos franciscanos de la Provincia de Castilla bajo su encomienda ${ }^{60}$. Ello ya establecía un precedente lejano para que, desde los primeros momentos del reinado de Enrique II, éste ya incluyera entre sus preocupaciones en materia eclesiástica el atender al buen estado del clero franciscano, coincidiendo en esta empresa con la opinión del papado, que, contando para ello con la colaboración regia, enviará en 1373 un grupo de reformadores franciscanos capitaneados por el Maestro en Teología y Provincial de Aquitania, Arnaldo Serrano ${ }^{61}$, lo que constituyó uno de los primeros precedentes reformadores de un monarca Trastámara. A ello se unió enseguida el otorgamiento de privilegios reales en favor de algunos conventos de franciscanos y clarisas, algunos de los cuales habían quedado en condiciones penosas al término de la guerra civil. Así, por ejemplo, entre los favorecidos se contaron, entre otros: Santa Clara de Carrión ${ }^{62}$, Palenzuela, en Tierra de Campos ${ }^{63}$, o algunas nuevas fundaciones como San Francisco del Ferrol ${ }^{64}$ y San Francisco de Bermeo ${ }^{65}$.

60 Luis CARRIÓN, Privilegio del ney Sancho IV, el Bravo, a los Franciscanos, «Archivo Ibero-Americanow, III (1916), 126- 131.

61 Lucca WADDINGO, ob. cit., IV, pp. 182-183.

62 José GARCía ORÓ, Francisco de Asís, p. 309.

63 lbid., pp. 311-312.

64 Manuel de CASTRO, Cónica de la Provincia franciscana de Santiago, p. 222. Véase también: Atanasio LÓPEZ, El convento de San Francisco del Fomol, «Eco Franciscanow, 31 (1914), 72 y 35 (1918), 179-183.

6s José García ORÓ, Francisco de Asís, p. 360. 
El siguiente paso en el proceso reformador se producirá con el comienzo de la reforma villacreciana, probablemente iniciada hacia 1377 y que, en buena parte, coincide en su primera fase con el reinado de Juan I, gran convencido de la necesidad del esfuerzo reformador ${ }^{66}$. Según algunos cronistas de la Orden Franciscana, con motivo de la legación en Castilla de Pedro de Luna, fray Pedro de Villacreces aconsejaría al monarca castellano en materia de reformas eclesiásticas ${ }^{67}$, por lo que conviene no descartar la hipótesis de un entendimiento e incluso una cierta colaboración entre el gran reformador franciscano y el propio monarca. Por entonces, algunas iniciativas reformadoras del reinado anterior, en el que la reina doña Juana Manuel manifestó siempre un gran interés por la expansión del franciscanismo, estaban comenzando a cuajar, favoreciendo las nuevas iniciativas fundacionales, sobre todo en la versión femenina de la reforma, representada por las clarisas. El monasterio de Santa Clara de Palencia, como fundación de Enrique II, representaba un buen exponente del modelo monástico que se pretendía generalizar en el monacato femenino ${ }^{68}$; otro tanto sucedía con Santa Clara la Real de Toledo, muy vinculado al apoyo nobiliario y regio ${ }^{69}$. Un nuevo foco de reformismo franciscano y, en particular clarisano, se unirá a los que se acaban de mencionar cuando, en 1380, Clemente VII nombre a una persona tan vinculada a la realeza Trastámara como fray Fernando de Illescas como Visitador de Santa Clara de Tordesillas, con carácter vitalicio ${ }^{70}$. Mientras, otros monasterios iniciaban las primeras aproximaciones hacia la observancia sin que faltase en ello la influencia regia, tal como sucedió, por ejemplo, en Santa Clara de Benavente ${ }^{71} 0$ en San Francisco de Cuéllar ${ }^{72}$.

Si en tiempos de Juan I una parte significativa de la iniciativa reformadora había sido protagonizada por alguien tan próximo al monarca como su propio confesor real, fray Fernando de Illescas, en tiempos de Enrique III será recogido el testigo por otro confesor real, fray Juan Enríquez, lo que nos pone de nuevo sobre la pista de que estamos ante una empresa que no está, ni mucho menos, al margen de lo que constituye un objetivo político de la monarquía del momento. En efecto, fray Juan Enríquez, confesor de Enrique III, como Custodio de Toledo, primero, y luego como Ministro Provincial de Castilla, realizará una importante labor de potenciación de saneamiento, en todos los sentidos, de las condiciones de vida de los monasterios franciscanos y clarisanos bajo su jurisdicción ${ }^{73}$.

El reinado de Juan II representa un momento de gran impulso en el proceso de afirmación de la observancia franciscana en Castilla, siendo el empeño regio en esta materia bastante notorio. En 1428 , se solicitará por el rey al papado el establecimiento de garantías que evitasen cualquier perturbación para los eremitorios y centros observantes, a veces tan contestados por los conventuales. Tal petición se

66 XiMénez SAMANIEGo, Anales de la Reforma, p. 452.

67 Domingo HeRNAEZ DE LA TORRE, Cbrónica de la provincia de Burgos de la Regular Observancia de Nuestro Padre San Francisco, Madrid, 1722, p. 109.

68 José GARCía ORÓ, Francisco de Asís, pp. 306-307 y A. ALVAREZ ReYero, ob. cit., p. 149.

69 José GARCí ORÓ, Francisco de Asís, Pp. 379-380.

70 Atanasio LÓPEZ, Fray Francisco de lllescas, p. 244.

71 Manuel de CASTRO, Crónica de la provincia franciscana de Santiago, pp. 80-81.

72 José GARCí ORÓ, Francisco de Asis, p. 326.

73 lbid., p. 370. 
traducirá el 9 de julio de 1428 en la bula Quanto acceptius ". Otras bulas otorgadas por solicitud regia, como, por ejemplo, la Apostolicae Sedis, de 1434, contribuirán a asegurar una mayor independencia de gobierno para los observantes frente a los conventuales".

Si la demanda ante Roma de un marco estatutario más definido, en favor de la Observancia, será una de las líneas de actuación por parte de Juan II, la otra línea consistirá en la reformación observante de centros concretos, materia en la que tanto la intervención directa del monarca, como de franciscanos personalmente vinculados al mismo, constituirán factores definitivos para el éxito de la empresa.

A instancias de Juan II, se iniciará, en 1439, la reforma de los franciscanos de Orense, ante su lamentable estado de relajación ${ }^{16}$. También con el apoyo regio, ocurriría otro tanto en conventos franciscanos de Salamanca, Benavente, La Coruña, Zamora y Cabeza de Alba ". Según algunos cronistas de la reforma franciscana, la reforma del importante monasterio de San Francisco de Salamanca conocerá la intervención de personajes tan vinculados a Juan II como fray Sancho de Canales, confesor de la reina Doña María, o del propio fray Alonso de Palenzuela ${ }^{78}$. Otro personaje vinculado al círculo cortesano de Juan II, fray Francisco de Soria, realizará una intensa actividad reformadora, siendo nombrado, a petición del rey, reformador de los conventos franciscanos de Segovia, según bula de Eugenio IV de $1432{ }^{79}$. Pronto se conseguiría un gran crédito como reformador eficaz, siendo solicitados sus servicios para diversos monasterios de clarisas como Santa Clara de Medina de Pomar ", Santa María de Comesa ", Santa Clara de Burgos "2, Santa Clara de Carrión de los Condes ${ }^{83}$ y Santa Clara de Segovia ${ }^{84}$. El propio Juan II se encargará de nombrar los reformadores de algunos eremitorios, como, por ejemplo, el de Santa María de Montesclaros, en la diócesis de Burgos, entregados a los observantes fray Juan y fray Pedro de Medina ${ }^{\text {as }}$. Incluso en aquellos casos en que la imposición de la vía observante tomó unas ciertas dimensiones violentas, la actuación de la monarquía será claramente decidida en favor de no detener su avance, tal como sucedió, por ejemplo, en San Francisco de Palencia, donde la expulsión de los conventuales se produjo a instancias de la intervención del arcediano de Toro Rodrigo Enríquez, que actuó en nombre de Juan II ${ }^{*}$.

La labor reformadora, que había dado tantos pasos durante el reinado de Juan II, no se detendrá durante el revuelto reinado de Enrique IV. Ya antes de acceder al

74 Fidel LEJARZA y Ángel URIBE, Intraducción, p. 140.

7s Bullarium, I, n. 126.

7 Manuel BANDín, Los origenes de la Observancia en la Provincia de Santiago, "Archivo Ibero-Americanow, XXXIII (1930), p. 350 .

17 Fidel LejARZA y Ángel URIBE, Intraducción, p. 79.

78 Manuel BANDíN, art. cit., Pp. 351.352.

79 Bullarium, I, n. 384.

8) Ibid., I, n. 403.

81 lbid., I, n. 388.

82 lbid., I, n. 496.

83 Ibid., I, n. 392.

84 lbid., I, n. 478.

85 lbid., I, n. 521 .

Mo Ibid., I, n. 797, 798 y 799. 
trono había mostrado un notable interés por el problema de la expansión de la Observancia y por el erradicamiento de la relajación que se observa en algunos conventos franciscanos, por lo que impetrará ante Nicolás $\mathrm{V}$ que se nombre un visitador para los monasterios de clarisas de Castilla que no será otro que el ya conocido fray Sancho de Canales ${ }^{\text {" }}$. Sin embargo, a pesar de las amplias facultades concedidas a este reformador por la mediación regia, buena parte de su labor quedará sin desarrollar por su pronto fallecimiento ${ }^{* *}$.

Ya comenzado su reinado, durante el primer año del mismo, tendrá que llevar a cabo una intervención el monarca, como consecuencia del enfrentamiento surgido entre los conventuales de Segovia y los observantes de la misma ciudad, cuestión en la que mediaría el Maestro fray Alonso de Espina, también observante y, por entonces, confesor real "*y. Así se llegaría a la decisión regia de ceder unas casas del propio monarca en las afueras de la ciudad para construir un monasterio franciscano, el de San Antonio, reservado a los observantes, fundación que será autorizada por Calixto III al año siguiente del enfrentamiento con los conventuales, en $1455^{\text {*). }}$. Siete años más tarde, y a petición regia, se comenzará la reforma de los conventuales de Segovia y Madrid, tras aceptar Pío II, tal como rezaba la propuesta regia, que fuera la Custodia de Santoyo la encargada de llevar a cabo esta reforma ". Un apoyo equivalente se producirá por parte del rey hacia las clarisas segovianas que precisaban de su reforma y de la reconstrucción de su monasterio "'.

Al igual que en Segovia, Enrique IV favorecerá otras iniciativas reformadoras en favor de la Observancia. Así sucederá, por ejemplo, en Toledo, en donde la vida religiosa de los conventuales se hallaba muy deteriorada, pidiendo Enrique IV, junto con algunos nobles, la intervención de Pío II en favor del asentamiento de la Observancia ${ }^{93}$, encontrándose otro caso similar para los franciscanos de Badajoz ${ }^{94}$, no faltando tampoco las actuaciones de la reina Juana en favor de la expansión clarisa, de lo que será buen exponente la fundación, por su intervención, de un

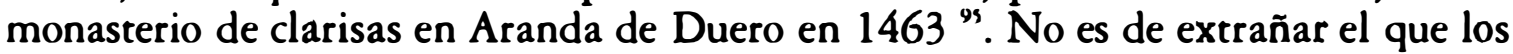
propios cronistas de la Orden Franciscana reconozcan la intensa actividad desplegada desde la Corte castellana durante este reinado solicitando diversas intervenciones pontificias que contribuyeran a consolidar los avances de la Observancia en el reino ". Con todo ello quedarían establecidos firmes precedentes de lo que habrá de ser la reforma en tiempos de los Reyes Católicos "7.

87 Ibid., I, n. 1.715.

8* Ángel URIBE, Primer ensayo de reforma franciscana, p. 266.

89 Diego de VAlerA, Memorial, cap. IV, p. 5.

\%) Bullarium Franciscanum continens. Constitutiones.. Calixti III, Pii II et Pauli II, Nova Series, II (1455-

1471), edic. de J.M. Pou y Martí, Florencia, 1939, n. 16.

"José GARCí ORÓ, Francisco de Asís, p. 320.

92 Ibid., pp. 321-322.

93 Bullarium, II, n. 1032.

91 lbid., n. 1.044.

9s Ángel URIBE, Primer ensayo de reforma franciscana, p. 277.

\% Lucca WADDINGO, ob. cit., VI, p. 481.

97 Véase: José GARCí ORÓ, Cisneros y la reforma del clero español en tiempos de los Reyes Católicos, Madrid, 1971. 


\section{EL FRANCISCANISMO COMO DEVOCIÓN EN LA REALEZA TRASTÁMARA}

La presencia de miembros del franciscanismo en momentos significativos del devenir político castellano, su propia presencia en la Corte, el predominio de los franciscanos entre los confesores reales, el interés regio por la reforma de las costumbres de la vida religiosa en los diversos monasterios franciscanos del reino, así como su empeño en favor de la prosperidad de la Observancia, nada de ello puede ser enteramente entendido si no tenemos presente un cierto componente devocional de la familia regia hacia todo lo que significaba la orden franciscana. Componente que excedió del propio ámbito de la familia real para afectar a amplios sectores de la nobleza cortesana, encontrándose exponentes máximos de este hecho ya en tiempos de los Reyes Católicos.

Seguramente, los precedentes, en este aspecto de lo devocional, no supondrían un factor secundario. Alfonso XI se había mandado enterrar con el hábito franciscano, el cual ya exhibió en vida . Esto seguramente habría contribuido a que los primeros monarcas Trastámara se aferrasen a esta lejana referencia franciscanista que, de alguna manera, les podía aportar elementos complementarios de legitimidad.

Son muchas las referencias que cabe alegar para poner de manifiesto la presencia de una no despreciable línea devocional franciscanista entre los monarcas de la dinastía trastámara que nos conduciría hasta los Reyes Católicos como momento de culminación de tal tendencia.

Entre los miembros de la familia de Enrique II destacaría, en este sentido, la infanta doña Leonor, su hija, que en su testamento dejó como herederos universales al monasterio de monjas clarisas de Todos los Santos, extramuros de Valladolid, y al convento de San Francisco de Valladolid ". Según señala el cronista franciscano Hernáez de la Torre, la familia real, en tiempos de Juan I, con el propio monarca a la cabeza, contaría entre sus expresiones de franciscanismo con su notable devoción hacia el eremita y reformador de la Orden, fray Pedro de Villacreces, indicando, además, que toda su Casa y Familia Real respiraba grande devoción a la Orden Seráfica. La madre del rey, doña Juana Manuel, ni en vida ni en muerte dejó el hábito de Santa Clara; tampoco faltaría esta tendencia devocional en el propio Fernando de Antequera, siendo el mismo rey Enrique III un destacado ejemplo de devoción franciscanista ${ }^{100}$.

En efecto, Enrique III representaría uno de los mejores ejemplos de devoción franciscanista entre los monarcas Trastámara. El cronista Waddingo alude a él señalando que Rex iste fuit dewotissimus $S$. Francisco ${ }^{101}$. Entre las primeras decisiones que tomó este monarca al salir de su minoridad se cuenta la de poner bajo su real protección a todos los conventos y personas de la Orden de los Menores, considerando algunos autores que tal decisión fue resultado del consejo del influyente fray Fernando de Illescas ${ }^{102}$. También se ha llamado la atención sobre el hecho de que

9 Biblioteca nacional, Ms. 3.840, fol. 455.

99 Bullarium, I, n. 487.

100 Domingo HeRNAEZ DE LA TORRE, ob. cit., p. 101.

101 Lucce WADDINGO, ob. cit., V, p. 54.

102 BIBLIOTECA NACIONAL, Ms. 3.840, fol. 72. 
frecuentemente utilizase este monarca en sus desplazamientos como lugares habituales para residencia de la familia real conventos de la Orden Franciscana. En San Francisco de Toro nacería el que habría de ser con el tiempo Juan II ${ }^{103}$. Algunos miembros de la familia real ingresarían en conventos franciscos, tal como sucedió con doña Isabel y doña Inés, tías del monarca, que profesarían en Santa Clara de Toledo ${ }^{104}$. El testamento del monarca también se encontraría en esta misma línea de hechos, encargando a sus testamentarios, entre los que figuran dos franciscanos, el levantamiento de un monasterio de esta Orden o que se reparta el dinero que esto costare entre los diversos monasterios de la misma Orden para asegurar su mejor conservación ${ }^{105}$. También en su testamento pondrá de manifiesto su interés por asegurar la presencia de un confesor franciscano junto a su hijo, el futuro monarca, recayendo su elección sobre fray Alfonso de Alcocer ${ }^{106}$. Su enterramiento, por propia decisión, con el hábito franciscano o la incorporación a sus armas del cordón característico de la Orden ${ }^{107}$ completan este perfil franciscanista del monarca. Su mujer, la reina y regente Catalina de Lancaster, no se podría sustraer a esta influencia, tal como lo demuestran sus preocupaciones reformadoras y la designación de dos testamentarios franciscanos ${ }^{109}$.

Sobre Juan II se asegura que ejercería una notable influencia fray Alonso de Borox, de ejemplar actividad como predicador evangélico y como modelo de celo religioso ${ }^{109}$. Una de las decisiones de más claro contenido devocional y franciscanista de este monarca sería la tomada en 1436 por la que se estableció que el 4 de octubre se celebrase en todo el reino el día de San Francisco como una fiesta principal, atendiéndose para ello a la devoción general que despertaba el santo y la que le profesó su padre, Enrique III, nacido el día de San Francisco ${ }^{110}$.

Catalogado Enrique IV por sus detractores como de irreligioso, también ofreció a lo largo de su vida alguna expresión de devoción franciscana. Seguramente, el hecho más señalado se produjo cuando, tras la muerte del que sería canonizado como san Diego de Alcalá, acaecida en 1463, acudió a visitar su cuerpo, que se mantenía incorrupto y que ya, se decía, había producido algunos milagros. El mismo monarca, maravillado del prodigio, oró ante su presencia y, según el cronista Waddingo, padeciendo fuertes dolores en un brazo, lo extendió hacia el difunto, quedando curado de ellos ${ }^{11}$. Sería, precisamente, la iniciativa real, ya en tiempos de Carlos I, la que acabaría desembocando en la canonización de este miembro de la Orden Franciscana ${ }^{112}$.

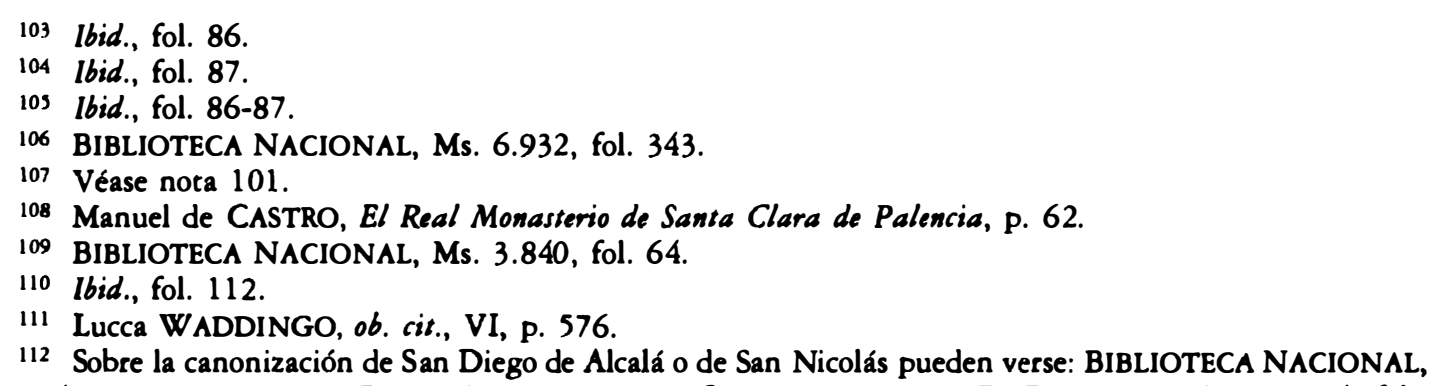
Ms. 5.734 y BIBlioteCA DEL REAL MONASTERIO DE SAN LORENZO DE EL ESCORIAL, Ms. \&.11.14, fols. 1-108. 
Finalmente, la actitud devocional hacia la Orden Franciscana de la reina Isabel la Católica ha sido amplia y documentadamente puesta de manifiesto en un estudio específico sobre la materia "'.

\section{CONCLUSIÓN}

Algunos autores han hecho referencia, con gran acierto, al ambiente franciscanista que predominó, desde el punto de vista de las corrientes espirituales, en la España de fines del siglo XV, entreverándose tal ambiente franciscanista con una cierta corriente mesiánica de diversa procedencia no totalmente ajena a dicho ambiente "1". A partir de las consideraciones precedentes, podemos ahora afirmar que este franciscanismo es el resultado de una larga trayectoria que experimenta un proceso de ampliación y de profundización en el conjunto de la etapa trastámara. A lo largo de ésta, el franciscanismo tuvo una proyección en la vida política que, si no se puede calificar como de intensa -porque no llegó a serlo-, sí se puede considerar, en cambio, como significativa y, sobre todo, ininterrumpida, pudiéndose valorar tal hecho como un tenue reflejo del arraigo que el franciscanismo había tomado en las formas de experiencia religiosa de la época.

JOSÉ MANUEl NiETO SORIA Universidad Complutense, Madrid

113 José MESSEgUer FernÁNDEZ, Franciscanismo de lsabel la Católica, "Archivo Ibero-Americanow, XIX (1959), 153-195.

iii Véase la obra de Alain MILHOU, Colón y su mentalidad mesiánica en el ambiente franciscanista espariol, Valladolid, 1983. 


\section{PROSOPOGRAFÍA POLÍTICO-ECLESIÁSTICA FRANCISCANA DE CASTILLA (1366-} 1475)

AGUILAR, Fray Alfonso de: (OFM). Confesor de Enrique III.

ALCALÁ, Fray Diego de (1400-1463): (OFM). Reformador franciscano. Misionero en Canarias (1441-1447). Hecho milagroso sobre Enrique IV (1463). Canonizado (1588).

ALCOCER, Fray Alonso: (OFM). Confesor de Enrique III. Embajador de Enrique III por el Cisma (1405-1406). Ministro Provincial de la Provincia Franciscana de Castilla (14091414).

ALFONSO DE CUENCA, Juan: (OFM). Abad de Alcalá. Capellán de Juan II (1441).

ANTIGUA, Fray Juan de la: (OFM). Capellán de Juana Pimentel, esposa de Álvaro de Luna. Protegido y colaborador de Álvaro de Luna.

ARGUELlO, Fray Alfonso (+1429): Embajador de Castilla por el Cisma (1401). Confesor del infante don Fernando de Antequera. Provincial Franciscano de Castilla. Obispo de León (1403). Obispo de Palencia (1415). Embajador de Castilla en la Coronación de Fernando I de Aragón (1414). Embajador en Aragón para la boda del infante don Alfonso (1415). Obispo de Sigüenza (1417). Arzobispo de Zaragoza (1419). Canciller Mayor de Aragón.

BADÁN DE MAYORGA, Fray Diego: (OFM). Provincial franciscano de Santiago. Obispo de Badajoz (1409). Obispo de Cartagena (1415). Obispo de Plasencia (1422). Fundador de un Studium de artes liberales en Mayorga de Campos.

BOROX, Fray Alfonso de: (OFM). Eremita en Ocaña. Comisario Provincial de los Observantes de Castilla. Ministro Provincial de Castilla. Nuncio Pontificio en Castilla (1444). Vicario Provincial de Castilla (1447). Consejero eventual de Juan II.

CANALES, Fray Sancho de: (OFM). Maestro en Teología. Confesor de la reina Doña María, mujer de Juan II. Protegido de Juan II. Reformador de San Francisco de Salamanca (1441). Reformador y visitador de los conventos franciscanos de Plasencia, Molina y Soria. Custodio de los Observantes de Castilla y León. Visitador de Santa Clara de Valladolid. Visitador de Santa Clara de Tordesillas.

CÓRDOBA, Fray Pedro: (OFM). Franciscano Observante. Colector Pontificio de Eugenio IV en Castilla (1445).

CUÉLlAR, Fray Andrés de: (OFM). Fraile de San Francisco de Cuéllar. Vinculado a la familia real. Confesor eventual de miembros de la familia real. Pensionado vitalicio por Juan II (1407).

ENRÍQUEZ, Fray Juan: (OFM). Fraile en San Francisco de Toledo. Confesor de 
Enrique III. Custodio de Toledo (1395). Visitador de las clarisas de Toledo. Ministro Provincial de Castilla. Testamentario de Enrique III. Obispo de Lugo (1409-1417). Conservador de Santa Clara de Toledo. Colaborador de Fernando de Antequera.

ESPINA, Fray Alonso: (OFM). Confesor de Enrique IV. Predicador de la Cruzada (1456). Regente de los teólogos de San Francisco de Salamanca. Obispo de Termópilas (1491). Auxiliar del Obispo de Oviedo Juan Arias (1491).

GONZÁLEZ DE OPTA, Fray Juan: Reformador franciscano enviado a Castilla por Gregorio XI (1373). Protegido de Enrique II.

ILLESCAS, Fray Fernando: (OFM). Estudios en el Colegio de Santiago de París. Profesor en la Universidad de Valladolid. Embajador de Juan I por el Cisma (1380). Visitador de Santa Clara de Tordesillas (1380). Capellán Pontificio de Clemente VII (1382). Embajador de Castilla ante el rey de Navarra (1383). Embajador de Castilla en Portugal (1385 y 1389). Predicador Real de Juan I. Confesor Real de Juan I. Embajador de Juan I ante el Duque de Lancaster (1387). Consejero de Juan I. Privado de Juan I. Testamentario de Juan I. Ayo de Enrique III en su minoría. Confesor Real de Enrique III. Embajador de Castilla en Francia (1396). Consejero de Juan II. Confesor Real de Juan II. Embajador de Castilla en el Concilio de Constanza (1415).

LOGROÑO, Fray Juan de: (OFM). Vicario de Canarias. Fundador del convento de Sanlúcar de Barrameda. Protegido de Juan II.

LÓPEZ DE RIBADENEYRA, Fray Diego: (OFM). Maestro en Teología. Confesor de don Enrique de Trastámara (luego Enrique II).

MANRIQUE DE LARA, Rodrigo: (OFM). Embajador de Catalina de Lancaster por el Cisma (1406).

MEDINA, Fray Juan: (OFM). Franciscano Observante. Restaurador del eremitorio de Santa María de Montes Claros de Burgos por encargo de Juan II.

MEDINA, Fray Pedro: (OFM). Franciscano Observante. Restaurador del eremitorio de Santa María de Montes Claros de Burgos por encargo de Juan II.

OÑA, Fray Rodrigo: (OFM). Nuncio Pontificio en Castilla (1445).

ORGAZ, Fray Francisco de: (OFM). Nuncio Pontificio en Castilla (1445).

PALENCIA, Fray Lope: (OFM). Guardián de San Francisco de Palencia, Reformador Observante de San Francisco de Palencia (1444). Protegido de Juan II.

PALENZUELA, Fray Alonso de: (OFM). Maestro en Teología. Predicador de Juan II. Confesor Real de Juan II. Provincial franciscano de Santiago. Reformador Observante. Embajador de Enrique IV ante Pío II (1458). Obispo de Ciudad Rodrigo (1460). Embajador de Enrique IV en Inglaterra (1467). Consejero Real. Obispo de Oviedo (1469-1485). Embajador de Isabel I ante Sixto IV (1474).

PEÑA, Fray Pedro de la: (OFM). Nuncio pontificio en Castilla (1445).

PEÑALVER, Fray Juan de: (OFM). Confesor del arzobispo de Toledo Alfonso Carrillo. Cofundador de San Francisco de Alcalá de Henares. Reformador Observante.

PISTOIA, Pedro de: (OFM). Nuncio Pontificio en Castilla (1445). Vicario franciscano en Andalucía.

PLASENCIA, Fray Diego de: (OFM). Reformador franciscano en Castilla por nombramiento de Gregorio XI (1371). Protegido de Enrique II.

REGALADO, Fray Pedro: (OFM). Eremita en el Abrojo de Valladolid. Vicario- 
Guardanal del Abrojo. Reformador franciscano. Continuador de Fray Pedro de Villacreces. Consejero eventual de Juan II.

SALAMANCA, Fray Fernando de: (OFM). Nuncio pontificio en Castilla (1444).

SALINAS, Fray Lope de (+1463): Colaborador de Fray Pedro de Villacreces. Reformador franciscano.

SAJA, Fray Luis de: (OFM). Custodio y Vicario visitador de los Franciscanos en la Provincia de Santiago. Custodio y Vicario visitador de los franciscanos en la Provincia de Castilla. Reformador de monasterios franciscanos en Salamanca, Zamora, Cabeza de Alba, Benavente y La Coruña. Protegido de Juan II. Nuncio Apostólico de Eugenio IV en Castilla la Vieja (1444). Colector Pontificio en Castilla la Vieja (1445).

SAN ISIDORO, Fray Fernando de: (OFM). Nuncio Pontificio en Castilla (1445).

SANTOYO, Fray Pedro de: (OFM). Reformador Observante en Castilla. Reformador de San Francisco de Valladolid. Protegido de Juan II.

SERRANO, Fray Arnaldo de: (OFM). Ministro Provincial de Aquitania. Reformador franciscano enviado a Castilla por Gregorio XI a Castilla (1373). Protegido de Enrique II.

SORIA, Fray Francisco: (OFM). Maestro en Teología. Confesor de la reina Doña Blanca de Navarra. Embajador del rey de Navarra en Castilla (1430). Consejero eventual de Juan II de Castilla. Reformador y visitador de las clarisas de Medina de Pomar, Tordesillas, Santa Clara de Burgos, Santa Clara de Carrión, Santa María de Comesa (Reinosa) y Santa Clara de Segovia. Pesquisidor real de los herejes de Durango (1442). Juez real de los pesquisidores de Durango.

VARAYZ, Fray Pedro: (OFM). Confesor de Blanca de Navarra. Embajador de Juan II de Navarra en Castilla (1438).

VILLACRECES, Fray Pedro de (+1422): (OFM). Bachiller en Teología por Salamanca. Estudios en París. Eremita reformador franciscano. Fundador de los eremitorios de La Salceda, La Aguilera (1404) y el Abrojo (1415). Representante de Castilla en el Concilio de Constanza (1416). Consejero eventual de Juan II.

VILlaRREAL, Fray Alfonso de: (OFM). Nuncio de Enrique IV ante Pío II (1463). Nuncio de Enrique IV ante Sixto IV. Capellán pontificio. Abad comendatario de Santa María de Monfero, del Císter, en la archidiócesis de Santiago de Compostela (1463). 